\title{
Avaliação Microbiológica dos Produtos de Higiene Pessoal das Indústrias de Cosméticos de Goiânia e Região Metropolitana
}

\author{
Lorena L. I. Teodoro, leda M. S. Torres \& Nathalia P. Barbosa
}

A avaliação microbiológica em produtos de higiene pessoal constitui uma etapa importante no que se refere à segurança do usuário e à qualidade do produto, visto que a carga microbiana elevada pode acarretar problemas de saúde. O objetivo do trabalho foi verificar o cumprimento das exigências acerca da qualidade microbiológica de produtos de higiene pessoal (shampoos e condicionadores) de nove indústrias de cosméticos de Goiânia e região. As amostras foram analisadas de acordo com os parâmetros nacionais e internacionais de qualidade, verificando e quantificando a presença de microrganismos. Realizou-se a contagem de bactérias e fungos viáveis totais e pesquisa do patógenos $P$. aeruginosa em 18 amostras. Os resultados das amostras avaliadas, $11.11 \%$ de shampoos e condicionadores analisadas, não estão dentro dos limites permitidos. Ambas apresentaram contaminação fúngica e bacteriana, acima dos limites descritos na legislação vigente. Ambas as amostras apresentaram o patógeno pesquisado $P$. aeruginosa. Estes resultados indicam que muitos produtos disponíveis no mercado apresentam qualidade inadequada, demonstrando falhas no controle de qualidade. Conclui-se que as indústrias brasileiras ainda necessitam de padrões de controle de qualidade e boas práticas de fabricação que garantam um produto final com qualidade para a saúde e beleza do consumidor.

Palavras Chave: cosméticos; shampoo; condicionador; controle de qualidade.

Microbiology in personal care products is an important component that hinders user safety and quality product, since high microbial load can lead to health problems. The objective of this study was to verify compliance with the requirements regarding the microbiological quality of personal hygiene products (shampoos and conditioners) of nine cosmetic industries in Goiânia and in the region. The samples were analyzed according to national and international quality parameters, verifying and quantifying the presence of microorganisms. A viable bacterial and fungal count and a $P$. aeruginosa survey were performed on 18 samples. The results of the analyzed samples, $11.11 \%$ of the analyzed shampoos and conditioners are not within the limits of contamination, above the limits established in the current legislation. Both samples showed the pathogen P. aeruginosa. These results indicate that many products available in the market present inadequate quality, demonstrating failures in quality control. It is concluded that Brazilian industries still need quality control standards and good manufacturing practices that ensure a final product with quality for the health and beauty of the consumer.

Keywords: cosmetics; shampoo; conditioner, quality control. 


\section{Introdução}

Segundo legislação vigente, Cosméticos, Produtos de Higiene e Perfumes "são preparações constituídas por substâncias naturais ou sintéticas, de uso externo nas diversas partes do corpo humano, pele, sistema capilar, unhas, lábios, órgãos genitais externos, dentes e membranas mucosas da cavidade oral, com o objetivo exclusivo ou principal de limpá-los, perfumá-los, alterar sua aparência e ou corrigir odores corporais e ou protegê-los ou mantê-

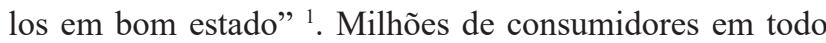
mundo utilizam produtos de higiene pessoal e cosméticos (HPPC) e os seus ingredientes, todos os dias ${ }^{2,3}$.

Os cosméticos são aplicados principalmente na pele, cabelo e unhas. São produtos usados com frequência em todo o mundo para manter e melhorar o aspecto geral da pele, por exemplo, boca, mão, olhos, cabelos, etc. ${ }^{4}$. Produtos para cuidados pessoais incluem uma grande variedade de produtos e tipos de formulação, tais como sabonetes, shampoo e produtos de higiene pessoal, protetores solares, perfumes, hidratantes corporal e facial, tintura de cabelo, maquiagens, batons, cremes dentais, produtos de higiene oral, desodorantes e muitos outros ${ }^{5}$.

O Brasil é um dos maiores mercados mundiais consumidores de cosméticos. A utilização de produtos de higiene pessoal, como shampoos e condicionadores é rotina dos brasileiros. A diversidade dos produtos e quantidade de produtos no mercado pode ser causa de preocupação para os órgãos de controle de qualidade ${ }^{6}$.

Os Shampoos reduzem as tensões superficiais entre os cabelos e as sujidades, pois contêm tensoativos catiônicos, aniônicos, anfóteros e não iônicos ${ }^{7}$. Cremes condicionadores capilares são emulsões do tipo óleo/água, que têm como agente emulsivo primário um tensoativo catiônico. Sua principal função é corrigir modificações ocasionadas pelo uso do shampoo sobre os cabelos, no que diz respeito à carga elétrica ${ }^{8}$.

Shampoos e condicionadores capilares são cosméticos de uso tópico não estéreis, que admitem limitado número de microrganismos viáveis não patogênicos e determinam ausência de microrganismos patogênico em $1 \mathrm{~g}$ ou $1 \mathrm{ml}$ do produto, segundo a legislação brasileira ${ }^{9}$.
Cargas microbianas elevadas alteraram a estabilidade do produto, levando à sua deterioração, mas ocorrem ainda, mudanças físicas e químicas que acarretam alterações, como quebra da estabilidade, alteração do $\mathrm{pH}$ e das características organolépticas (cor, odor, sabor e textura), e inativação das substâncias ativas e excipientes da formulação ${ }^{10,11,12}$, além de prejuízos econômicos e comprometimento da visibilidade da empresa ${ }^{13}$.

Produtos cosméticos constituem uma fonte rica em nutrientes para o crescimento de microrganismos devido às suas composições. Produtos contendo matérias-primas de origem natural e com elevado teor de água são os que apresentam maior susceptibilidade à contaminação ${ }^{14}$.

O uso de produtos contaminados associados às infecções devem ser avaliados considerando-se a finalidade, as condições sob as quais o produto será utilizado, a frequência e o tempo exposto. Em indivíduos saudáveis, o contato com produtos contaminados, normalmente, não representa sérios problemas. Entretanto, em pacientes imunodeficientes (leucemia, diabetes, AIDS) ou de extrema idade (crianças ou idosos), pode ocorrer infecção ${ }^{15,16}$.

Os organismos, frequentemente encontrados em produtos cosméticos, são os patogênicos oportunistas e incluem Pseudomonas, enterobactérias, Flavobacterium e Staphylococcus ${ }^{16}$. Para conseguir um produto cosmético com controle de qualidade microbiológico, torna-se necessário baixos índices de contaminação dentro dos padrões das especificações, bem como manter o controle de qualidade eficaz desde as matérias-primas até o produto final.

No Brasil, até 1997, não existiam padrões de caráter oficial, porém o Instituto Nacional de Controle de Qualidade em Saúde/ Fundação Oswaldo Cruz (INCQS/ FioCruz), em seu manual de análises microbiológicas especificava que produtos utilizados para a área dos olhos deveriam conter uma carga contaminante viável menor que $50 \mathrm{UFC} / \mathrm{g}(\mathrm{mL})$ e, um limite de $10^{3} \mathrm{UFC} / \mathrm{g}(\mathrm{mL})$ para outros produtos, bem como ausência de Pseudomonas aeruginosa, Staphylococcus aureus e enterobactérias em $1 \mathrm{~g}(\mathrm{~mL})$ para qualquer produto cosmético ${ }^{16}$.

Compêndios oficiais como a European Pharmacopeia 17 não dispõem de limites microbianos para cosméticos, 
mas constam padrões para preparações de uso tópico, que especificam um limite de:

a. $10^{2}$ bactérias aeróbias e fungos/g ou $\mathrm{mL}$ da amostra;

b. não mais que 10 enterobactérias e outros Gram negativos/g ou $\mathrm{mL}$ da amostra $\mathrm{e}$

c. ausência de P. aeruginosa e S. aureus em $1 \mathrm{~g}$ ou $\mathrm{mL}$ da amostra.

A Farmacopeia Americana ${ }^{18}$ não apresenta limites microbianos para cosméticos e, em relação a medicamentos, os limites constam nas respectivas monografias dos produtos, sendo que o significado das contaminações deve estar de acordo como uso e a natureza de cada produto e ao potencial de risco que esta contaminação acarretaria para o usuário. Cita ainda que em produtos de uso tópico devem estar ausentes microrganismos como $S$. aureus e P. aeruginosa.

No Brasil, a legislação criada em 1999 (RDC 481/99) 9 é a que rege até os dias de hoje. Os produtos cosméticos sujeitos ao controle microbiológico foram divididos em Tipo I e Tipo II. Segundo a Portaria, os cosméticos são classificados, conforme a função, local de aplicação e faixa etária, e para cada subgrupo foram especificados limites microbianos conforme relacionado a seguir na Tabela 1 .

Tabela 1. Subgrupos dos produtos cosméticos e local de aplicação

\begin{tabular}{|c|c|}
\hline SUBGRUPO & LOCAL DE APLICAÇÃO \\
\hline \multirow{2}{*}{ TIPO I } & Produtos para uso infantil \\
\cline { 2 - 2 } & Produtos para área dos olhos \\
\cline { 2 - 2 } & Produtos para contato com mucosas \\
\hline \multirow{2}{*}{ TIPO II } & $\begin{array}{c}\text { Demais produtos susceptíveis a } \\
\text { contaminação }\end{array}$ \\
\hline
\end{tabular}

Os limites de contaminação para os grupos de produto acabado, são:

Grupo I:

a. Contagem de microrganismos totais aeróbios, não mais de $10^{2} \mathrm{UFC} / g$ ou $\mathrm{mL}$ (limite máximo $5,0 \times 10^{3} \mathrm{UFC} / \mathrm{g}$ ou mL);

b. Ausência de Pseudomonas aeruginosa em $1 \mathrm{~g}$ ou $1 \mathrm{~mL}$;

c. Ausência de Staphylococcus aureus em $1 \mathrm{~g}$ ou $1 \mathrm{~mL}$; d. Ausência de coliformes totais e fecais em $1 \mathrm{~g}$ ou $1 \mathrm{~mL}$;

e. Ausência de clostrídios sulfito redutores em $1 \mathrm{~g}$ (exclusivamente para talcos).

Grupo II:

a. Contagem de microrganismos totais aeróbios, não mais de $10^{3} \mathrm{UFC} / \mathrm{g}$ ou $\mathrm{mL}$ (limite máximo 5,0 x $10^{3} \mathrm{UFC} / \mathrm{g}$ ou $\mathrm{mL}$ );

b. Ausência de Pseudomonas aeruginosa em $1 \mathrm{~g}$ ou $1 \mathrm{~mL}$;

c. Ausência de Staphylococcus aureus em $1 \mathrm{~g}$ ou $1 \mathrm{~mL}$;

d. Ausência de Coliformes totais e fecais em $1 \mathrm{~g}$ ou $1 \mathrm{~mL}$;

e. Ausência de Clostrídios sulfito redutores em $1 \mathrm{~g}$ (exclusivamente para talcos).

Assim, este trabalho teve por objetivo avaliar a qualidade microbiológica de produtos cosméticos (shampoos e condicionadores capilares), industrializados na cidade de Goiânia e região metropolitana - Goiás, com o intuito de verificar se esses encontram-se em consonância com os limites microbianos estabelecidos pela $5^{\mathrm{a}}$ edição da Farmacopeia Brasileira (F.Bras. 2010) e pela RDC 481/99 (ANVISA, 1999) e, portanto, são apropriados para o uso.

\section{Metodologia}

\section{AMOSTRAGEM}

Foram utilizadas dezoito amostras de produtos cosméticos, (shampoos e condicionadores) de nove indústrias de cosméticos de Goiânia e região metropolitana. A fórmula foi escolhida, levando-se em consideração a existência de materiais que são frequentemente utilizados na manipulação de produtos de higiene para aplicação capilar, bem como aqueles que apresentam um risco maior de contaminação por serem de origem vegetal, como extratos de mamona, camomila, jaborandi e outros, utilizados como princípios ativos das fórmulas.

Esta amostragem foi submetida aos testes de contagem microbiana e pesquisa de microrganismos patogênicos, segundo as técnicas da Farmacopeia Americana (UAP 23), farmacopeia Brasileira $4^{\mathrm{a}}$ edição e do Guia da Associação Brasileira de Cosmetologia. 


\section{Preparação das amostras}

As embalagens primárias das amostras, antes de serem abertas, foram higienizadas com algodão embebido em etanol a $70 \%$ e homogeneizadas mediante agitação manual durante cerca de um minuto.

Pesou-se $10 \mathrm{~g}$ de cada amostra e adicionou-se a $90 \mathrm{ml}$ de caldo lecitina de soja a $0,2 \%$ e polisorbato 20 a $3,0 \%$ para proporcionar inativação do conservante, obtendo-se assim uma diluição a 10- ${ }^{1}$.

\section{PROCEDIMENTO UTILIZADO NA CONTAGEM} DE BACTÉRIAS AERÓBIAS VIÁVEIS EM PLACA

A dispersão correspondente à diluição $10-^{1}$ foi submetida à diluição decimal seriada, usando-se $90 \mathrm{ml}$ de caldo caseína-soja até a diluição a $10-^{3}$. De cada diluição, foram transferidas alíquotas de $1 \mathrm{ml}$ na base de placas de Petri em duplicata, esterilizadas e previamente identificadas, adicionando-se cerca de $18 \mathrm{ml}$ de Ágar Casoy, previamente fundido e resfriado a $45^{\circ} \mathrm{C}$.

Homogeneizaram-se as alíquotas (meio de cultura e amostra) empregando-se movimentos circulares, em sentido horário e anti-horário alternadamente. Incubaram-se as placas a $30-35^{\circ} \mathrm{C}$ por até 96 horas em posição invertida, com leitura diária.

Ovalor médio do número de UFC, correspondente à duplicata, foi multiplicado pela recíproca da respectiva diluição, a fim de calcular a carga contaminante viável por grama da amostra.

\section{PROCEDIMENTO UTILIZADO NA IDENTIFICAÇÃO E CONTAGEM DE FUNGOS E LEVEDURAS}

O procedimento analítico foi o mesmo utilizado no item 2.3, usando-se $1 \mathrm{~mL}$ das respectivas diluições em Placas de Petri, em duplicata, vertendo-se cerca de $18 \mathrm{~mL}$ de Ágar Sabouraud-dextrose, com incubação à $25^{\circ} \mathrm{C}$ por sete dias. $\mathrm{O}$ valor médio de UFC correspondente à duplicata foi multiplicado pela recíproca da respectiva diluição, a fim de calcular a carga fúngica por grama da amostra.

\section{PESQUISA DE PATÓGENOS}

Recomenda-se para pesquisa de patógenos promover enriquecimento não seletivo que deve ser efetuado a partir da diluição inicial. O meio nutritivo aqui utilizado para o enriquecimento foi o caldo de caseína-soja.

Foram transferidos $10 \mathrm{ml}$ da diluição inicial para $90 \mathrm{ml}$ do caldo de caseína-soja. Foram incubados por 48 horas a $30-35^{\circ} \mathrm{C}$.

\section{Pesquisa de Pseudomonas aeruginosa}

A partir do caldo de enriquecimento não seletivo, com o auxílio da alça de platina, transferiuse o material para a placa de Petri, contendo ágar cetrimida, previamente preparado. Para isso, utilizouse o método de estria por esgotamento, para isolar o eventual contaminante. As placas foram incubadas de forma invertida a $30-35^{\circ} \mathrm{C}$ por 48 horas. As colônias suspeitas foram transferidas para o ágar de detecção de fluoresceína e ágar de detecção de piocianina, incubadas de forma invertida a $30-35^{\circ} \mathrm{C}$ por três dias e depois foram observadas sob a luz UV de $254 \mathrm{~nm}$.

Para confirmação dos resultados, foram realizados os testes de Coloração de Gram.

\section{COLORAÇÃO DE GRAM}

Com o auxílio da alça de platina, previamente flambada, retiraram-se colônias da Placa de Petri e preparou-se um esfregaço das amostras em estudo. As lâminas foram secas ao ar. Fixou-se o material à lâmina, passando rapidamente três vezes na chama do Bico de Bunsen. Cobriram-se as lâminas com solução de cristal violeta, por 1 minuto. Esgotaram-se as lâminas e lavaram-nas com água deionizada. Cobriram-se as lâminas com solução de fucsina por 30 segundos. Esgotaram-se as lâminas e lavaram-nas com água deionizada. Descoraram-se as lâminas com álcool até o desprendimento da violeta (cerca de 10 segundos). Esgotaramse as lâminas e lavaram-nas com água deionizada. Cobriram-se as lâminas com solução de fucsina por 30 segundos. Esperou-se as lâminas secarem à temperatura ambiente e observaram-e ao microscópio com o objetivo de imersão.

\section{Resultados e Discussão}

De acordo com os resultados obtidos e mostrados na Tabela 2, as amostras 13 e 14 apresentaram carga microbiana superior aos limites microbiológicos vigentes (limite máximo 5,0 x 103 UFC/g ou mL). 
Tabela 2. Análise microbiológica das dezoito amostras, sendo nove shampoos e nove condicionadores, de nove indústrias de cosméticos

\begin{tabular}{|c|c|c|c|c|}
\hline EMPRESA & AMOSTRA & $\begin{array}{c}\text { Contagem Total de } \\
\text { Bactérias Mesófilas } \\
\text { Aeróbias }\end{array}$ & $\begin{array}{c}\text { Contagem Total de } \\
\text { Bolores }\end{array}$ & $\begin{array}{c}\text { Contagem Total de } \\
\text { Leveduras }\end{array}$ \\
\hline \multirow{2}{*}{$\mathbf{A}$} & A 01 & $<1,0 \times 10^{1} \mathrm{UFC} / \mathrm{g}$ & $<1,0 \times 10^{1} \mathrm{UFC} / \mathrm{g}$ & $<1,0 \times 10^{1} \mathrm{UFC} / \mathrm{g}$ \\
\hline & A 02 & $<1,0 \times 10^{1} \mathrm{UFC} / \mathrm{g}$ & $<1,0 \times 10^{1} \mathrm{UFC} / \mathrm{g}$ & $<1,0 \times 10^{1} \mathrm{UFC} / \mathrm{g}$ \\
\hline \multirow{2}{*}{ B } & B 01 & $<1,0 \times 10^{1} \mathrm{UFC} / \mathrm{g}$ & $<1,0 \times 10^{1} \mathrm{UFC} / \mathrm{g}$ & $<1,0 \times 10^{1} \mathrm{UFC} / \mathrm{g}$ \\
\hline & B 02 & $<1,0 \times 10^{1} \mathrm{UFC} / \mathrm{g}$ & $<1,0 \times 10^{1} \mathrm{UFC} / \mathrm{g}$ & $<1,0 \times 10^{1} \mathrm{UFC} / \mathrm{g}$ \\
\hline \multirow{2}{*}{ C } & $\mathrm{C} 01$ & $<1,0 \times 10^{1} \mathrm{UFC} / \mathrm{g}$ & $<1,0 \times 10^{1} \mathrm{UFC} / \mathrm{g}$ & $<1,0 \times 10^{1} \mathrm{UFC} / \mathrm{g}$ \\
\hline & $\mathrm{C} 02$ & $<1,0 \times 10^{1} \mathrm{UFC} / \mathrm{g}$ & $<1,0 \times 10^{1} \mathrm{UFC} / \mathrm{g}$ & $<1,0 \times 10^{1} \mathrm{UFC} / \mathrm{g}$ \\
\hline \multirow{2}{*}{ D } & D 01 & $<1,0 \times 10^{1} \mathrm{UFC} / \mathrm{g}$ & $<1,0 \times 10^{1} \mathrm{UFC} / \mathrm{g}$ & $<1,0 \times 10^{1} \mathrm{UFC} / \mathrm{g}$ \\
\hline & D 03 & $<1,0 \times 10^{1} \mathrm{UFC} / \mathrm{g}$ & $<1,0 \times 10^{1} \mathrm{UFC} / \mathrm{g}$ & $<1,0 \times 10^{1} \mathrm{UFC} / \mathrm{g}$ \\
\hline \multirow{2}{*}{$\mathbf{E}$} & E 01 & $<1,0 \times 10^{1} \mathrm{UFC} / \mathrm{g}$ & $<1,0 \times 10^{1} \mathrm{UFC} / \mathrm{g}$ & $<1,0 \times 10^{1} \mathrm{UFC} / \mathrm{g}$ \\
\hline & E 02 & $<1,0 \times 10^{1} \mathrm{UFC} / \mathrm{g}$ & $<1,0 \times 10^{1} \mathrm{UFC} / \mathrm{g}$ & $<1,0 \times 10^{1} \mathrm{UFC} / \mathrm{g}$ \\
\hline \multirow{2}{*}{$\mathbf{F}$} & F 01 & $<1,0 \times 10^{1} \mathrm{UFC} / \mathrm{g}$ & $<1,0 \times 10^{1} \mathrm{UFC} / \mathrm{g}$ & $<1,0 \times 10^{1} \mathrm{UFC} / \mathrm{g}$ \\
\hline & F 02 & $<1,0 \times 10^{1} \mathrm{UFC} / \mathrm{g}$ & $<1,0 \times 10^{1} \mathrm{UFC} / \mathrm{g}$ & $<1,0 \times 10^{1} \mathrm{UFC} / \mathrm{g}$ \\
\hline \multirow{2}{*}{ G } & G 01 & $7,8 \times 10^{3} \mathrm{UFC} / \mathrm{g}$ & $2,3 \times 10^{2} \mathrm{UFC} / \mathrm{g}$ & $<1,0 \times 10^{1} \mathrm{UFC} / \mathrm{g}$ \\
\hline & G 02 & $6,3 \times 10^{3} \mathrm{UFC} / \mathrm{g}$ & $3,3 \times 10^{1} \mathrm{UFC} / \mathrm{g}$ & $<1,0 \times 10^{1} \mathrm{UFC} / \mathrm{g}$ \\
\hline \multirow{2}{*}{$\mathbf{H}$} & Н 01 & $<1,0 \times 10^{1} \mathrm{UFC} / \mathrm{g}$ & $<1,0 \times 10^{1} \mathrm{UFC} / \mathrm{g}$ & $<1,0 \times 10^{1} \mathrm{UFC} / \mathrm{g}$ \\
\hline & $\mathrm{H} 02$ & $<1,0 \times 10^{1} \mathrm{UFC} / \mathrm{g}$ & $<1,0 \times 10^{1} \mathrm{UFC} / \mathrm{g}$ & $<1,0 \times 10^{1} \mathrm{UFC} / \mathrm{g}$ \\
\hline \multirow{2}{*}{$\mathbf{I}$} & I 01 & $<1,0 \times 10^{1} \mathrm{UFC} / \mathrm{g}$ & $<1,0 \times 10^{1} \mathrm{UFC} / \mathrm{g}$ & $<1,0 \times 10^{1} \mathrm{UFC} / \mathrm{g}$ \\
\hline & I 02 & $<1,0 \times 10^{1} \mathrm{UFC} / \mathrm{g}$ & $<1,0 \times 10^{1} \mathrm{UFC} / \mathrm{g}$ & $<1,0 \times 10^{1} \mathrm{UFC} / \mathrm{g}$ \\
\hline
\end{tabular}

Pelos dados da Tabela 2, percebe-se que aproximadamente $11.11 \%$ das amostras de shampoos e condicionadores analisadas não estão dentro dos limites permitidos, ou seja, $5000 \mathrm{UFC} / \mathrm{g}$ ou $\mathrm{mL}$.

Pelos dados da Tabela 2, verifica-se que 11,11\% apresentaram contagem total de bactérias mesófilas aeróbias e essas mesmas amostras (11,11\%) apresentaram contagem total de bolores e nenhum apresentou contagem total de leveduras fora do padrão estabelecido pelas legislações vigentes.

As duas amostras (G 01 e G 02) contaminadas por bactérias e bolores foram analisadas, a fim de verificar a contaminação de patógenos. Estas foram submetidas ao teste de confirmação de coloração de Gram, para diferenciação de bactérias gram positivas e gram negativas.
Conforme a Tabela 3, ambas as amostras apresentaram resultado confirmando a presença de $P$. aeruginosa.

Organismos domésticos podem contaminar uma fábrica por diversas razões. Sistema inadequado de preservação; a aceitação de critérios para produtos acabados não é suficientemente rigorosa. Procedimentos de limpeza e sanitização inadequados; a fábrica falha no cumprimento de BPF porque os procedimentos são inadequados ou porque não são eficazmente realizados. Matérias-primas contaminadas; os microrganismos podem ter se adaptado aos conservantes dos produtos. Método de testes inadequados; o sistema de recuperação e/ou condições de cultura não evitam o transporte de conservantes ou permitem o crescimento de microrganismos; falta de acompanhamento do caso quando é detectada uma contaminação (Orth, 1997). 
Tabela 3. Característica da Pseudomonas aeruginosa em meios seletivos.

\begin{tabular}{|c|c|c|c|}
\hline $\begin{array}{c}\text { Meio } \\
\text { Seletivo }\end{array}$ & $\begin{array}{c}\text { Característica } \\
\text { Morfotintorial } \\
\text { da colônia }\end{array}$ & $\begin{array}{c}\text { Fluorescência } \\
\text { luz UV } \\
\text { AMOSTRA } \\
\text { G 01 }\end{array}$ & $\begin{array}{c}\text { Fluorescência } \\
\text { luz UV } \\
\text { AMOSTRA } \\
\text { G 02 }\end{array}$ \\
\hline $\begin{array}{c}\text { Ágar para } \\
\text { detecção de } \\
\text { Fluoresceína }\end{array}$ & $\begin{array}{c}\text { Normalmente } \\
\text { esverdeada }\end{array}$ & Esverdeada & Esverdeada \\
\hline $\begin{array}{c}\text { Ágar para } \\
\text { detecção de } \\
\text { Piocianina }\end{array}$ & $\begin{array}{c}\text { Normalmente } \\
\text { esverdeada }\end{array}$ & Azul & Azul \\
\hline
\end{tabular}

Levantamento realizado no Brasil mostrou que cerca de $40 \%$ dos cosméticos adquiridos no mercado estavam contaminados. Análise de cremes no Reino Unido mostraram que a maioria das amostras apresentaram carga contaminante total entre 300 e $10^{3} \mathrm{UFC} / \mathrm{g}$, sendo que nos casos com carga superior, foram atribuídos como causa a aplicação inadequada das Boas Práticas de Fabricação ${ }^{19}$. Além disto a preocupação por esta contaminação é mais relevante para os produtos, pois pode ser facilmente detectada ocasionando perdas nas vendas e na credibilidade do fabricante ${ }^{20}$.

Semelhante a outros estudos, a ocorrência de baixa frequência de fungos e leveduras ocorrem devido à presença de parabenos, como conservante, na maioria dos cosméticos, pois são particularmente ativos contra fungos e leveduras. Segundo a ANVISA ${ }^{6}$, a função do conservante não é utilizada, a fim de compensar as más práticas de fabricação. Muitos fabricantes o utilizam em altos teores na tentativa de manter a carga microbiana dentro do limite especificado, desconsiderando os danos à saúde decorrente dessa prática. Entretanto, a comprovação deste fato só pode ser feita mediante a identificação e o doseamento do teor das substâncias utilizadas como conservante nessas formulações, que não foram objetivos deste trabalho.

A presença de Pseudomonas aeruginosa em produtos acabados constitui um problema na indústria cosmética, porque este microrganismo está amplamente disseminado na água, solo e também no ar. Sua necessidade nutricional é mínima, podendo sobreviver e multiplicar-se sob condições inadequadas para outros microrganismos ${ }^{21}$.
Segundo $\operatorname{Orth}^{20}$, a presença de microrganismos, a disponibilidade de água, condições favoráveis ao crescimento, composição da matéria prima, condições durante as colheitas, processamento, fabricação e armazenagem, são fatores que influenciam nos níveis de contaminação. Tais fatos devem ser monitorados pois os danos causados pela contaminação dos produtos são irreversíveis.

\section{Conclusões}

Com o trabalho, pode-se concluir que das dezoito amostras analisadas, duas não atendem aos limites microbianos (bactérias, bolores e $P$. aeruginosas) no que diz respeito ao controle de qualidade microbiológico, estabelecido pelas legislações vigentes.

A maioria dos shampoos e dos condicionadores de cabelos das indústrias de cosméticos de Goiânia e região metropolitana analisados podem ser considerados satisfatórios. Entretanto, em relação à amostragem, a quantidade de produtos apresenta-se relevante.

Vale ressaltar a importância do controle de qualidade microbiológico desde a qualificação de fornecedores até a entrega do produto final. Este não deve ser encarado pelo setor industrial como mais um gasto supérfluo, mas antes de tudo, como uma maneira de garantir produtos seguros e de qualidade para o consumidor.

\section{Referências}

1. Brasil, Agência Nacional de Vigilância Sanitária (ANVISA). Diário Oficial da União. Resolução RDC no 306, de 07 de dezembro de 2004.

2. Abihpec, Associação Brasileira da Indústria de Higiene Pessoal, Perfumaria e Cosméticos. III Caderno de Tendências, 2014-2015.

3. Nohynek, G.J.; Antignac, E.; RE, T.; Toutain, H. Safety assessment of personal care products/cosmetics and their ingredientes. Toxicology and Applied Pharmacology. 2010, 243, 239-259.

4. Pareek, A.; Jain, V.; Ratan, Y.; Sharma, S.; Jain, P.K.; Dave, V. Mushrooming of Herbal's in New Emerging Market of Cosmaceuticals, International Journal of Advanced in Pharmaceutical \& Bio Science. 2012, 2 (4), 473-480.

5. Antignac, E.; Nohynek, G.J.; Re, T.; Clouzeau, J.; Toutain, H. Safety of botanical ingredients in personal care products/ cosmetics. Food 
and Chemical Toxicology. 2011, 49, 324-341.

6. ANVISA. Agência Nacional de Vigilância Sanitária. Resolução RDC No 162 , de 11 de setembro de 2001. Estabelece a lista de substâncias de ação conservante para produtos de higiene pessoal, cosméticos e perfumes. Diário Oficial da União, 12 de setembro de 2001.

7. Corrêa M.A. Cosmetologia: ciência e técnica. São Paulo: Medfarma; 2012.

8. Ferreira A.O. Guia Prático da Farmácia Magistral. $2^{\mathrm{a}}$ ed. Juiz de Fora: Pharmabooks; 2002.

9. ANVISA. Agência Nacional de Vigilância Sanitária. Resolução RDC n$^{\circ} 481$, de 23 de setembro de 1999. Estabelece os parâmetros de controle microbiológico para os produtos de higiene pessoal, cosméticos e perfumes. Diário Oficial da União, 27 de setembro de 1999.

10. Medeiros, ACD, Porto KL, Paiva AVR, Procópio JVV. Análise de contaminantes microbiológicos em produtos comercializados em farmácia de manipulação. BioFar. 2007;1(1):1-12

11. Pinto TJA, Kaneko TM, Ohara MT. Controle biológico de qualidade de produtos Farmacêuticos, correlatos e cosméticos. $2^{\mathrm{a}}$ ed. São Paulo: Atheneu; 2003.

12. Kabara JJ.. Cosmetic and drug preservation: principles and practice. New York: Marcel Dekker; 1984.

13. Blume SI, Castelli RM, Ribeiro GA. Qualidade Microbiológica de cosméticos comercializados em lojaspo pulares da cidade de Pelotas/ RS. In: XVI Congresso de Iniciação Científica, Pelotas-RS; 2007;

14. Pinto T.J.A., Kaneko T.M., Ohara M.T. Controle biológico de qualidade de produtos farmacêuticos, correlatos e cosméticos. São Paulo: Atheneu; 2000.

15. De Lorenzo J.L. Microbiologia para o estudante de odontologia. São Paulo: Atheneu; 2004.

16. Albert, L.M. Manual de análises microbiológicas de cosméticos do INCQS/Fiocruz, Revista Aerosol \& Cosméticos. 1 ed. São Paulo, 1989 (Encarte Técnico), p. 10-18.

17. EUROPEAN PHARMACOPEIA. Supplement, 3 ed., Coincil of Europe, Strasbourg, 2001, 1704 p.

18. UNITED STATES PHARMACOPEIA - THE NATIONAL FORMULARY, 24 ed., Rockville, p. 2569, 2000.

19. Kollings, L.O. Controle de Qualidade Microbiológico Cosméticos. Revista Aerosol \& Cosméticos, São Paulo, V. 6, N. 34, p. 4-10, 1984.

20. Orth, Donald S. Organismos Domésticos. Revista Cosmetics \& Toiletries (Edição em Português), Los Angeles, V. 9, N. 3, p. 43-49, mai., /jun. 1997.
21. Nicoletti, Maria A. et al. Sistemas conservantes em formulações cosméticas. Revista Cosmetics \& Toiletries (Edição em Português), São Paulo, V. 9, N. 3, p. 28-33, mai.,/jun. 1997.

\section{Lorena L. I. Teodoro ${ }^{*}$, leda M. S. Torres $^{2} \&$ Nathalia P. Barbosa ${ }^{2}$}

${ }^{1}$ Faculdade Metropolitana de Anápolis. Av. Fernando Costa, 49 - Vila Jaiara St. Norte, Anápolis - GO, Brasil, CEP: 75064-780.

${ }^{2}$ Universidade Federal de Goiás. Faculdade de Farmácia. Rua 240, S/n - Setor Leste Universitário, Goiânia - GO, Brasil, CEP 74605-170.

\section{*E-mail: lorenalisita@hotmail.com}


